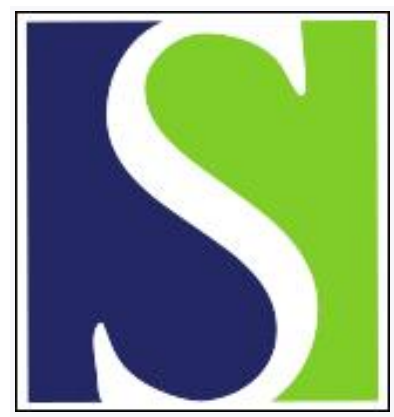

Scand J Work Environ Health 2018;44(1):96-105

https://doi.org/10.5271/sjweh.3680

Published online: 27 Oct 2017, Issue date: 01 Jan 2018

Is objectively measured sitting at work associated with low-back pain? A cross sectional study in the DPhacto cohort by Korshøj M, Hallman DM, Mathiassen SE, Aadahl M, Holtermann A, Jørgensen MB

Low-back pain (LBP) is a substantial health challenge. Sitting is believed to be a risk for LBP. The association of sitting at work and during whole days and intensity of LBP was investigated. Intensity ofLBP was measured on a 0-10 scale and sitting was measured by accelerometry. The associations between sitting and LBP were not significant.

Affiliation: National Research Centre for the Working Environment (NRCWE), Lersø Parkallé 105, 2100 Copenhagen, Denmark. mkl@nrcwe.dk.

Refers to the following texts of the Journal: 2017;43(3):269-278 2016;42(1):43-51 2006;32(4):294-299 2011;37(1):6-29

Key terms: accelerometer; back pain; DPhacto; DPhacto cohort; inactivity; low-back pain; musculoskeletal disease; musculoskeletal disorder; musculoskeletal pain; occupational health; occupational sitting; pain; physical activity; sedentary; sitting at work; temporal pattern; time pattern

This article in PubMed: www.ncbi.nlm.nih.gov/pubmed/29076513

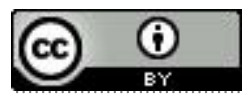




\title{
Is objectively measured sitting at work associated with low-back pain? A cross sectional study in the DPhacto cohort
}

\author{
By Mette Korshøj, PhD, ${ }^{1}$ David M Hallman, PhD, ${ }^{2}$ Svend Erik Mathiassen, PhD, ${ }^{2}$ Mette Aadahl, PhD, 3,4 \\ Andreas Holtermann, PhD, ${ }^{1,5}$ Marie Birk Jørgensen, $P h D^{1}$
}

\begin{abstract}
Korshøj M, Hallman DM, Mathiassen SE, Aadahl M, Holtermann A, Jørgensen MB. Is objectively measured sitting at work associated with low-back pain? A cross sectional study in the DPhacto cohort. Scand J Work Environ Health. 2018;44(1):96-105. doi:10.5271/sjweh.3680
\end{abstract}

\begin{abstract}
Objectives Low-back pain (LBP) is a substantial health challenge due to the risk for long-term sickness absence and early retirement. Several biomechanical exposures at work, including sitting, have been suggested to increase the risk for LBP. The objectives of this study were to determine (i) the extent to which temporal patterns and total amount of objectively measured sitting is associated with LBP intensity and (ii) whether selected modifiers influence these associations.
\end{abstract}

\begin{abstract}
Methods This cross sectional study uses baseline data from the Danish PHysical ACTivity cohort with Objective measurements (DPhacto) of physical activities in the cleaning, transport and manufacturing sectors. Peak intensity of LBP was collected by questionnaire on a $0-10$ scale and sitting was expressed in terms of total duration and temporal pattern, ie, time spent in brief bursts ( $\leq 5$ minutes), moderate periods ( $>5-\leq 20$ minutes), and prolonged periods of sitting ( $>20$ minutes); both during work and whole day (waking hours only). Associations were determined using linear regression in models accounting for moderation and confounding. Factors evaluated as moderators or confounders were assessed by questionnaire.
\end{abstract}

Results The population consisted of 704 participants. No significant associations were found between total duration or temporal patterns of sitting and LBP intensity, neither during work nor for the whole day. Body mass index (BMI) significantly moderated the association between sitting and LBP; participants with a high and low BMI showing a negative and positive association, respectively.

Conclusion Sitting was not independently associated with peak LBP intensity, suggesting other exposures are more powerful risk factors for LBP.

Key terms accelerometer; inactivity; musculoskeletal disease; musculoskeletal disorder; musculoskeletal pain; occupational health; occupational sitting; physical activity; temporal pattern; time pattern; sedentary.

Low-back pain (LBP) is a substantial health challenge in the general Danish population. In 2013, 47\% of workers in Denmark reported pain or discomfort in the back during the preceding 14 days (1). Severe LBP increases the risk for long-term sickness absence and early retirement (2) and has profound consequences for individuals, organizations, and society (3-5).
Biomechanical exposures at work, such as heavy lifting or awkward trunk postures, are believed to be key determinants of LBP (6). However, many traditional work tasks posing heavy physical work demands on the lower back while standing or walking have been replaced by sedentary tasks. Thus, sitting at work has been increasing during the last two decades $(7,8)$. A

\footnotetext{
${ }^{1}$ National Research Centre for the Working Environment (NRCWE), Lersø Parkallé 105, 2100 Copenhagen, Denmark

2 Department of Occupational and Public Health Sciences, Centre for Musculoskeletal Research, University of Gävle, Kungsbäcksvägen 47, 801 76 Gävle, Sweden

3 Research Centre for Prevention and Health, The Capital Region of Denmark, Nordre Ringvej 57, 2600 Glostrup, Denmark.

${ }^{4}$ Department of Public Health, Faculty of Health Sciences, University of Copenhagen, Øster Farimagsgade 5, 1014 Copenhagen, Denmark.

5 Department of Sports Science and Clinical Biomechanics, University of Southern Denmark, Campusvej 55, 5230 Odense, Denmark

Correspondence to: Mette Korshøj, NRCWE, Lersø Parkallé 105, 2100 Copenhagen, Denmark. [mkl@nrcwe.dk]
} 
Danish study from 2014 (9) showed that $40 \%$ of all employees in Denmark were sitting $>75 \%$ of their working hours. Even in blue-collar occupations, workers now appear to be exposed to considerable sitting during the working day (10-12). This suggests that effects of sitting may also be relevant to address in blue-collar occupations.

In theory, prolonged sitting at work could cause LBP due to limited posture variation $(13,14)$. This may, hypothetically, decrease flexibility and muscle strength in the lower back (15), which may in turn lead to disc degeneration, rupture, or herniation $(16,17)$. Yet, evidence supporting these hypothetical mechanisms of mechanical damage to tissues is not convincing. Furthermore, systematic reviews of the available evidence have not been able to verify a consistent association between sitting and LBP (18-20).

The inconsistent results may be due to the different methods used in previous studies to assess sitting, ie, self-reports, observations, or objective measurements, resulting in a dispersion in the extent and quality of information $(18,20)$. Self-reported sitting is less valid than sitting measured objectively, for instance by accelerometry $(21,22)$, due to recall bias $(23)$ or differential misclassification $(24,25)$. Thus, objectively measured sitting is preferable in the context of trustworthiness and also has the advantage of allowing detailed investigations of temporal sitting patterns $(10,12)$. The development of LBP has even been suggested to be associated with the temporal patterns of sitting $(18,26)$. A few recent studies have used accelerometer-based sitting data in studies of associations with $\operatorname{LBP}(11,27)$. However, these studies pointed in opposite directions: Gupta and colleagues (11) found that an increased amount of sitting was positively associated with LBP intensity while Lunde and colleagues (27) concluded that sitting was negatively associated with intensity of LBP. Only two studies have addressed associations between LBP and the temporal patterns of sitting, expressed in terms of the occurrence of prolonged uninterrupted periods of sitting (26) or as the frequency of transitions between sitting and other body postures, such as standing (18). Thus, further studies on objectively measured sitting and LBP are justified, focusing on both total amount and temporal patterns of sitting.

Therefore, the objectives of this paper were to (i) investigate the extent to which LBP is associated with the total amount and the temporal patterns of objectively measured sitting, both at work and for whole days, and (ii) investigate whether these associations are influenced by selected moderators.

Our main hypothesis was that more time spent sitting is associated with an increased level of LBP intensity, in particular if sitting occurs for long uninterrupted periods of time.

\section{Methods}

\section{Study design and population}

This study was based on data from the Danish PHysical ACTivity cohort with Objective measurements (DPhacto). Participants were recruited from $15 \mathrm{com}$ panies in the cleaning, transport, and manufacturing occupational sectors between December 2011 and March 2013 in collaboration with a large Danish labor union (21). The study was conducted according to the Helsinki declaration and approved by the Danish Data Protection Agency and local ethics committee (H-2-2012-011). All workers provided their written informed consent prior to participation. Baseline measures included questionnaires, objective measurements of anthropometrics, blood pressure and physical capacity, and objective measurements of physical activity and body postures based on accelerometry. Further details can be found in previous studies based on the DPhacto cohort (28, 29). The present study is a cross sectional analysis of baseline data.

Inclusion criteria for companies were that they allowed measurements to take place during paid working hours. Pregnant workers were excluded from participation in the study. Workers with allergy to bandages or adhesives were excluded from the objective monitorbased measurements (21).

Assessment of exposure. Objective data on sitting were collected using two accelerometers (ActiGraph GT3X+) (30), mounted on the skin at the front of the right thigh (medial between the iliac crest and the upper border of the patella) and at the trunk (at processus spinosus at the level of T1-T2) by adhesives (11, 12, 31). Participants wore the accelerometers for 4-6 days, 24 hours a day. During the measurement days, participants were asked to keep a diary stating: working hours, time off work, time in bed (when they went to bed and got up in the morning), and periods when they did not wear the accelerometers.

Data were sampled by the accelerometers at a frequency of $30 \mathrm{~Hz}$ with a dynamic range of $\pm 6 \mathrm{G}$ and a 12-bit precision. The accelerometers were initialized and data downloaded using the Actilife software version 5.5 (ActiGraph LLC, Pensacola, FL, USA). Accelerometer signals were low-pass filtered at $5 \mathrm{~Hz}$ using a fourthorder Butterworth filter and then split up in 2-s windows with $50 \%$ overlap. Then, the accelerometer data were analyzed using the customized software Acti4 (31). The Acti4 software determines a variety of body postures and activities and has shown a sensitivity of $99.9 \%$ and specificity of $100.0 \%$ for sitting in standardized field settings (31). Non-wear periods were identified when one or more of the following criteria applied: (i) 
the participant registered non-wear in the diary, (ii) the Acti 4 detected periods $>90$ minutes with zero acceleration, or (iii) missing data and/or artefacts were detected by visual inspection.

These analyses only included days where the participant had been working. Measurements during working hours were included if they were $\geq 4$ hours/day (continuous periods) or a duration of $\geq 75 \%$ of average wear time during work across days per participant. Similar inclusion criteria were used for the intervals during time-off work.

Sitting periods were determined using data from the trunk and thigh accelerometers (28) as periods when thigh inclination was $>45^{\circ}$ and trunk inclination was $<45^{\circ}$ relative to the recorded vertical reference position (11). Sitting during the whole day was calculated as the accumulated time in sitting while being awake, and expressed in percent of the total duration of the measurement day. For each participant, results were then averaged across days, and this average was used in the statistical models described below. Similarly, sitting during work was calculated for each participant by adding up periods of sitting during working hours for each measurement day, expressing the result as percent of working time that day, and averaging across days.

Temporal patterns of sitting were quantified using exposure variation analysis (EVA) (32). Uninterrupted periods of sitting were identified throughout the entire time line of the processed accelerometer signal. An interruption in sitting was defined to occur when nonsitting occurred for $\geq 5$ consecutive seconds. Sitting periods were then categorized according to duration (10): ie, brief bursts ( $\leq 5$ minutes), moderate periods $(>5-\leq 20$ minutes) and prolonged periods ( $>20$ minutes). For each participant, the mean daily duration (hours/ day) spent in each of the EVA categories for both working hours and the whole day was calculated by dividing the total accumulated duration of sitting in the specific category across all measurement days by the number of days. Additionally, the mean time spent in each EVA category was expressed as percent of the daily average of total wear-time, both during working hours and for the whole day.

The distributions of the categorized EVA data were skewed and therefore these variables were square root transformed before proceeding with further analyses. The square root transformation resulted in distributions closer to normal.

Assessment of outcome. Intensity of LBP was determined using the question: "In the last 3 months, state your worst pain in lower back" from the standardized Nordic Questionnaire for the analysis of musculoskeletal symptoms (33), with response options on an 11-point scale from 0 ("no pain") to 10 ("worst pain imaginable").
Assessment of potential confounders and moderators. A number of factors have been shown in previous research to be associated both with LBP and the amount of sitting; they were therefore considered as potential confounders: age (34); sex (34); smoking $(35,36)$; BMI $(37,38)$; level of occupational lifting (34); occupational sector (39); previously diagnosed with a herniated disc (40); leisure-time physical activity $(41,42)$; and intensity of physical activity during working hours (43, 44), measured as rate of perceived exertion and aerobic workload in this study.

Since the factors listed above may also act to moderate the association between sitting and LBP, the following factors were entered in the analysis through an interaction term (sitting $\times$ factor): age, sex, BMI, occupational sector, level of physical activity during leisure time, and intensity of physical activity during working hours. Factors were centered prior to their inclusion in interaction terms to reduce effects of collinearity between data in interaction and main effects.

Age was based on the date of birth for the participant. Sex was determined from the question: "Are you male or female?". Smoking was assessed by the question "Do you smoke?" using four response categories, which were merged into a dichotomized variable: yes ("yes, daily", "yes, sometimes") or no ("used to smoke", "I have never smoked"). Objective measurements of body weight (in kg; Tanita BC418) and height (in m; Seca model 123 1721009) were obtained, and used to calculate the BMI $\left(\mathrm{kg} / \mathrm{m}^{2}\right)$. Occupational lifting and carrying was assessed by a single item from the Danish Work Environment Cohort Survey (DWECS): "How much of your working time do you carry or lift?" with a 6-point response scale from 1 ("almost all the time") to 6 ("never"). Occupational sector was determined by the workplace of the participant and whether the participant stated to be working in administration (white-collar work) or production (blue-collar work). The following occupational sectors were represented: cleaning, manufacturing, transportation and administration (irrespective of occupational sector). A previous diagnosis with a herniated disc was assessed by the question: "Do you have herniated discs?" with the dichotomized response "yes" or "no". Moderate-to-vigorous leisure-time physical activity was assessed by the Acti4 software, adding up leisure time spent in one of the following activities: running, climbing stairs, and cycling. The accumulated time was expressed as percentage of the total measured leisure time and participants were classified into high or low level physical activity by a median split. Intensity of physical activity during working hours was measured by the rate of perceived exertion, assessed by the question: "How physically demanding do you normally consider your present work?" with a 10-point response scale from 1 ("sedentary, not demanding") to 10 ("very demand- 
ing"); and aerobic workload was assessed in terms of relative heart rate (45), with objectively measured resting heart rate and estimated maximal heart rate (46).

Social support and influence at work were determined by items from the Copenhagen Psychosocial Questionnaire (47). Influence at work was determined by the question: "Do you have a large degree of influence concerning your work?"; "Can you influence the amount of work assigned to you?". Social support was determined by: "Is there good cooperation between the management and the employees?"; "Is there good cooperation between the colleagues at work?" The response categories were on a 5-point scale, ranging from 1 ("always") to 5 ("never"). The scale were reversed and recoded to $0-4$; answers given for the two items were added up to a $0-8$ scale for each dimension as described in the questionnaire manual (available at: www.arbejdsmiljoforskning.dk). Thus, in the analyzed data, higher numbers indicate more influence and better social support.

Statistical analysis. Associations between sitting variables and LBP were determined using linear regression. The different variables of sitting [total sitting, EVA derivatives describing temporal patterns (brief bursts, moderate and prolonged sitting periods)] were analyzed during work and for the whole day in separate regressions. Exposure variables were square root transformed in order to better approach a normal distribution. Intensity of LBP was entered as a continuous variable. The assumption of a linear association between exposure and outcome was justified according to visual inspection of data plots.

Interaction terms between centered variables of exposure and potential moderator factors were included in the regression one by one. If the interaction term showed to influence the association between exposure and outcome significantly $(\mathrm{P}<0.10)$, the interaction term was included in the final model, and a complementary stratified analysis was conducted. Those potential moderator factors that did not significantly influence the association between sitting and LBP were instead considered as potential confounders.

Multicollinearity between the potential confounders was assessed by variance inflation; if substantial multicollinearity was present, the potential confounder was not included in the final model. Potential confounders were included in the final model one by one if they significantly $(\mathrm{P}<0.10)$ affected the association between exposure and outcome. Three sensitivity analyses were performed based on the final model. In the first, age and sex were added as forced confounders to the final model. In the second, social support and influence at work were added. This second sensitivity analysis could only be performed for cleaning and manufacturing since none of the participants from the transport sector received the questions regarding influence and support at work due to a technical error. In the third sensitivity analysis, the final model was run on a population excluding all participants reporting 0 on the LBP scale, ie, no LBP.

Additionally, analyses both for work and the whole day were conducted in which the EVA derivatives were expressed in percentages of total sitting, as opposed to percentages of the total measurement time, as above. These analyses were performed to determine the extent to which the temporal pattern of sitting was associated with LBP irrespective of total sitting.

\section{Results}

\section{Flow of participants}

Figure 1 shows the flow of the participants from DPhacto included in this study. Of the 909 participants that took part in the diurnal accelerometer measurements of sitting, 704 participants were included in the analysis, based on the quality criteria for accelerometer data described above.

Baseline characteristics of the study population. The DPhacto contains data from three occupational sectors, ie, cleaning, manufacturing, and transport, as well as the administrative staff within these occupational sectors. The study population included 704 of the participants in the DPhacto (figure 1), 312 females and 392 males (table 1), aged 18-68 years. The participants had a mean seniority in their current job of 13.0 [standard deviation (SD) 10.1] years (table 1).

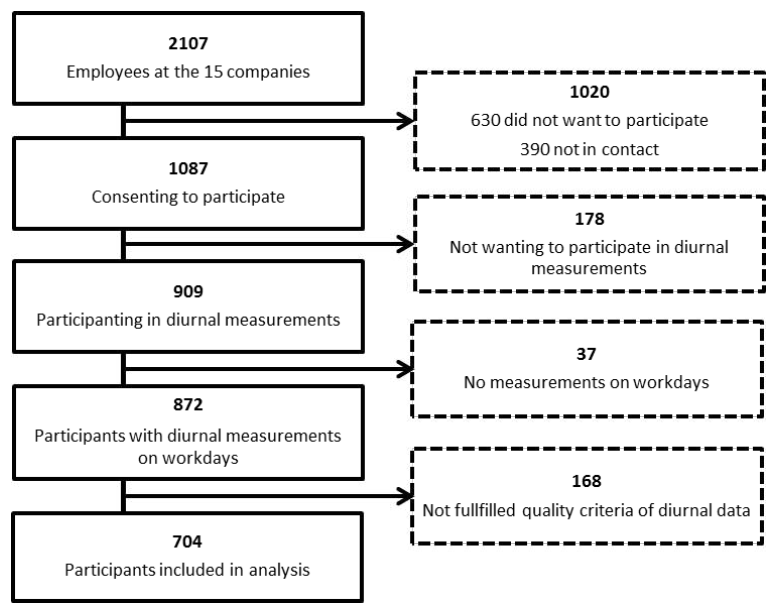

Figure 1. Flow of the participants 
Table 1. Baseline characteristics of the study population ( $N=704)$.

\begin{tabular}{|c|c|c|c|c|c|}
\hline & Mean & SD & $\mathrm{N}$ & $\%$ & Range \\
\hline Age (years) & 45.0 & 9.9 & 704 & & $18-68$ \\
\hline Sex (females) & & & 312 & 44.3 & \\
\hline Current smoker & & & 204 & 29.7 & \\
\hline Body mass index $\left(\mathrm{kg} / \mathrm{m}^{2}\right)$ & 27.4 & 4.9 & 688 & & $16.2-45.1$ \\
\hline$<25 \mathrm{~kg} / \mathrm{m}^{2}$ & & & 448 & 65.1 & \\
\hline$\geq 25 \mathrm{~kg} / \mathrm{m}^{2}$ & & & 240 & 34.9 & \\
\hline Lifting \& carrying at work (scale 1-6) & 3.6 & 1.5 & 700 & & \\
\hline$<50 \%$ of working hours & & & 412 & 58.9 & \\
\hline$\geq 50 \%$ of working hours & & & 288 & 41.1 & \\
\hline \multicolumn{6}{|l|}{ Occupational sector } \\
\hline Cleaning & & & 128 & 18.2 & \\
\hline Manufacturing & & & 472 & 67.0 & \\
\hline Transport & & & 62 & 8.8 & \\
\hline Administration & & & 42 & 6.0 & \\
\hline $\begin{array}{l}\text { Rate of perceived exertion at } \\
\text { work (scale 1-10) }\end{array}$ & 5.8 & 2.2 & 674 & & \\
\hline $\begin{array}{l}\text { Moderate-to-vigorous physical } \\
\text { activity during leisure (hours/day) }\end{array}$ & 0.5 & $<0.1$ & 704 & & $0.0-0.5$ \\
\hline $\begin{array}{l}\text { Peak low-back pain intensity in the } \\
\text { past } 3 \text { months (scale } 0-10 \text { ) }\end{array}$ & 3.4 & 3.1 & 701 & & \\
\hline 0 & & & 212 & 30.2 & \\
\hline $1-4$ & & & 228 & 32.5 & \\
\hline$\geq 5$ & & & 261 & 37.2 & \\
\hline Diagnosed with a herniated disc & & & 56 & 8.0 & \\
\hline $\begin{array}{l}\text { Total duration of included measure- } \\
\text { ments of working hours (hours) }\end{array}$ & 19.9 & 8.0 & 704 & & $4.0-51.3$ \\
\hline $\begin{array}{l}\text { Total duration of included } \\
\text { measurements of whole day (hours) }\end{array}$ & 42.9 & 15.7 & 704 & & $10.7-88.7$ \\
\hline $\begin{array}{l}\text { Included measurements of } \\
\text { working hours (hours/day) }\end{array}$ & 7.7 & 1.6 & 704 & & $3.3-14.5$ \\
\hline $\begin{array}{l}\text { Included measurements of } \\
\text { whole day (hours/day) }\end{array}$ & 16.8 & 1.7 & 704 & & $9.3-24.0$ \\
\hline $\begin{array}{l}\text { Occupational sitting } \\
\text { (\% working hours) }\end{array}$ & 33.2 & 21.8 & 704 & & $1.6-91.6$ \\
\hline Whole day sitting (\% whole day) & 43.9 & 12.6 & 704 & & $9.0-82.6$ \\
\hline
\end{tabular}

The mean intensity of LBP during the last 3 months was 3.4 (SD 3.1) on a $0-10$ point scale, where 10 indicated the worst imaginable pain (table 1). More than half of the population $(62.8 \%)$ reported a level of LBP $<5$ within the last 3 months and $30.2 \%$ reported to be painfree. Seventy-three percent of the population stated having $<31$ days with LBP during the last year and 24.3\% stated having no days with LBP during that period.

On average, accelerometer data were collected for 2.6 days for each participant (SD 1.0 day), in total comprising 19.9 hours (SD 8.0 hours) of work and 22.9 hours (SD 8.9 hours) of valid recordings off work (table 1). Cumulative distributions of the EVA derivatives describing the temporal pattern of sitting are shown in figure 2 .

\section{Building of statistical models}

Variance inflation estimates did not indicate any critical multicollinearity among the potential confounders.

The models including interaction terms between exposure variables and potential moderators only showed a significant interaction with BMI. Thus, only this interaction was entered in the final model, and other potential

\section{Sitting at work}

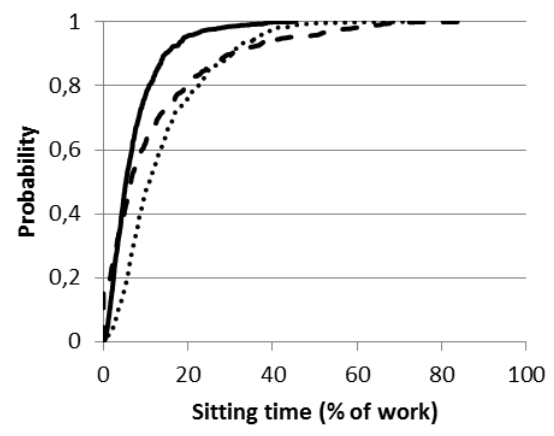

Whole day sitting

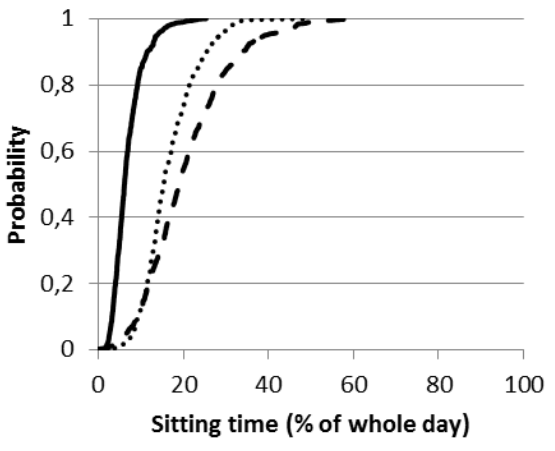

Figure 2. Cumulative probability distributions of exposure variation analysis (EVA) derivatives in the study population, ie, brief bursts (time in spent sitting $<5$ minutes), moderate periods (sitting periods of $>5-20$ minutes) and prolonged periods (sitting for more than $>20$ minutes) during work and the whole day.

moderators were entered as confounder main effect terms. Secondary, a complementary model stratified on high $\left(\geq 25 \mathrm{~kg} / \mathrm{m}^{2}\right)$ and low $\left(<25 \mathrm{~kg} / \mathrm{m}^{2}\right)$ BMI was applied.

Of the potential confounders, only diagnosis with a herniated disc and rate of perceived exertion affected the association between exposure and outcome significantly. Thus, the final model included these two confounders only.

\section{Primary analysis of association between sitting and LBP}

The results from the crude and final models describing the association between sitting and LBP are shown in table 2. Sitting during work and whole day were not significantly associated with LBP intensity in crude, univariate models, neither for the total sitting nor for the EVA derivatives reflecting the temporal patterns of sitting. However, BMI, as the only moderating factor, appeared to interact significantly with total amount of sitting and sitting in brief bursts and moderate periods both during work and whole day (table 2). 
Table 2. Associations between sitting (total time and temporal patterns (EVA derivatives)) during work and for the whole day (waking hours), and the intensity of low back pain (scale 0-10). 701 participants were included in the crude, univariate model (model 1) and 653 in the final model (model 2). [BMI=body mass index; $\mathrm{Cl}=$ confidence interval.] Significant $(\mathbf{P}<\mathbf{0 . 0 5})$ associations are marked with bold.

\begin{tabular}{|c|c|c|c|c|c|}
\hline & $\mathrm{R}^{2}$ & B & SE $P$ & P-value & $95 \% \mathrm{Cl}$ \\
\hline \multicolumn{6}{|l|}{ Sitting at work } \\
\hline \multicolumn{6}{|l|}{$\begin{array}{l}\text { Total (\% of occupational } \\
\text { hours spent sitting) }\end{array}$} \\
\hline Model $1^{\text {a }}$ & 0.002 & -0.07 & 0.06 & 0.28 & $-0.19-0.06$ \\
\hline Model $2^{\mathrm{b}}$ & 0.04 & 0.04 & 0.07 & 0.60 & $-0.10-0.17$ \\
\hline Sitting $\times$ BMI interaction & & -0.002 & 0.001 & 0.03 & $-0.005--0.0002$ \\
\hline \multicolumn{6}{|l|}{ Brief bursts ( $\leq 5$ minutes) } \\
\hline Model 1 a & 0.00 & -0.02 & 0.11 & 0.87 & $-0.23-0.19$ \\
\hline Model $2^{b}$ & 0.04 & -0.01 & 0.11 & 0.91 & $-0.23-0.20$ \\
\hline Sitting $\times$ BMI interaction & & -0.007 & 0.003 & 0.03 & $-0.01--0.0006$ \\
\hline \multicolumn{6}{|l|}{$\begin{array}{l}\text { Moderate periods (>5-20 } \\
\text { minutes) }\end{array}$} \\
\hline Model $1^{\text {a }}$ & 0.002 & -0.09 & 0.08 & 0.31 & $-0.25-0.08$ \\
\hline Model $2^{b}$ & 0.04 & 0.01 & 0.09 & 0.92 & $-0.17-0.18$ \\
\hline Sitting $\times B M I$ interaction & & -0.005 & 0.002 & 0.02 & $-0.009--0.0007$ \\
\hline \multicolumn{6}{|c|}{ Prolonged periods (>20 minutes) } \\
\hline Model 1 a & 0.0009 & -0.04 & 0.06 & 0.43 & $-0.16-0.07$ \\
\hline Model $2^{\mathrm{b}}$ & 0.04 & 0.05 & 0.06 & 0.41 & $-0.07-0.18$ \\
\hline Sitting $\times \mathrm{BMI}$ interaction & & -0.0009 & 0.002 & 0.62 & $-0.004-0.003$ \\
\hline \multicolumn{6}{|l|}{ Whole day sitting } \\
\hline \multicolumn{6}{|c|}{$\begin{array}{l}\text { Total (percentage of whole day } \\
\text { spent sitting) }\end{array}$} \\
\hline Model $1^{\text {a }}$ & 0.003 & -0.17 & 0.12 & 0.16 & $-0.41-0.07$ \\
\hline Model $2^{b}$ & 0.04 & 0.01 & 0.13 & 0.92 & $-0.24-0.27$ \\
\hline Sitting $\times$ BMI interaction & & -0.004 & 0.002 & 0.04 & $-0.008--0.0003$ \\
\hline \multicolumn{6}{|l|}{ Brief bursts ( $\leq 5$ minutes) } \\
\hline Model 1 a & 0.0001 & 0.04 & 0.18 & 0.81 & $-0.31-0.40$ \\
\hline Model 2 b & 0.03 & 0.08 & 0.18 & 0.68 & $-0.28-0.44$ \\
\hline Sitting $\times$ BMI interaction & & -0.01 & 0.01 & 0.03 & $-0.03--0.001$ \\
\hline \multicolumn{6}{|l|}{$\begin{array}{l}\text { Moderate periods (>5-20 } \\
\text { minutes) }\end{array}$} \\
\hline Model $1^{\text {a }}$ & 0.0007 & -0.11 & 0.15 & 0.49 & $-0.40-0.19$ \\
\hline Model $2^{b}$ & 0.04 & 0.02 & 0.16 & 0.90 & $-0.29-0.33$ \\
\hline Sitting $\times$ BMI interaction & & -0.01 & 0.004 & 0.01 & $-0.02--0.003$ \\
\hline \multicolumn{6}{|c|}{ Prolonged periods ( $>20$ minutes) } \\
\hline Model $1^{\mathrm{a}}$ & 0.003 & -0.15 & 0.10 & 0.15 & $-0.35-0.05$ \\
\hline Model $2^{b}$ & 0.03 & -0.04 & 0.11 & 0.71 & $-0.26-0.18$ \\
\hline Sitting $\times$ BMI interaction & & -0.0003 & 0.002 & 0.89 & $-0.005-0.004$ \\
\hline
\end{tabular}

a Model 1 is unadjusted (univariate).

${ }^{b}$ Model 2 is adjusted for herniated disc, rate of perceived exertion, and the interaction between sitting and BMI.

An alternative model, in which data on temporal patterns of sitting were expressed in percent of the total amount of sitting rather than in percent of the overall measurement time, did not show any significant associations of temporal patterns with LBP intensity, neither for sitting during work nor whole day.

\section{Stratified analyses of association between sitting and LBP}

An unadjusted analysis was conducted in sub-populations stratified on BMI (low $<25 \mathrm{~kg} / \mathrm{m}^{2}$ and high $\geq 25$ $\mathrm{kg} / \mathrm{m}^{2}$ ). These stratified analyses showed that among participants having a low BMI, more sitting (total, brief bursts, and moderate periods) was associated with an increased LBP intensity, both during work and whole day (table 3, figure 3). In contrast, among those having a high BMI, more sitting during work or for the whole day was associated with a decreased LBP intensity. The stratified analysis was additionally adjusted for herniated disc and rate of perceived exertion, just as the final model for the entire population; however, this adjustment didn't change the estimates numerically or statistically (results not shown).

\section{Sensitivity analyses}

All of the sensitivity analyses - one including age and sex as confounders, one including social support and influence at work as confounders, and one exploring associations only among participants with LBP $(\mathrm{N}=212)$ by excluding those reporting to have no LBP - resulted in numerically and statistically similar findings to those reported in table 2 (results not shown).

\section{Discussion}

We did not find any significant associations between total sitting and intensity of LBP (table 2), neither during work nor the whole day. Neither did we find associations between temporal patterns of sitting (brief bursts, moderate periods, prolonged periods) and intensity of LBP (table 2). Therefore, we rejected the hypothesis of a positive association between sitting and LBP intensity.

None of the previous studies addressing associations between sitting and $\operatorname{LBP}(11,19,20,27)$ considered the possible effect of moderating factors (20). Therefore, we investigated the extent to which the association between sitting and LBP was moderated by factors traditionally classified as confounders $(24,25)$. Among the investigated potential moderating factors, only BMI significantly interacted with sitting, and was therefore included in the final model. An analysis stratified on high and low BMI indicated that in the low BMI $(<25$ $\mathrm{kg} / \mathrm{m}^{2}$ ) group LBP intensity increased with an increased amount of sitting, while LBP intensity decreased with an increased amount of sitting in the high BMI ( $\geq 25$ $\mathrm{kg} / \mathrm{m}^{2}$ ) group (figure 3, table 3); even if none of these associations were very strong. An explanation for the association between increased sitting time and decreased LBP among those with high BMI could be that sitting indirectly protects against alternative non-sitting activities that may cause added strain on the back among those with high BMI. However, high BMI may also reflect high muscle mass rather than obesity, as suggested by Fogelholm (48). If so, the mechanisms behind BMI as a potential modifier are less straight forward and should 

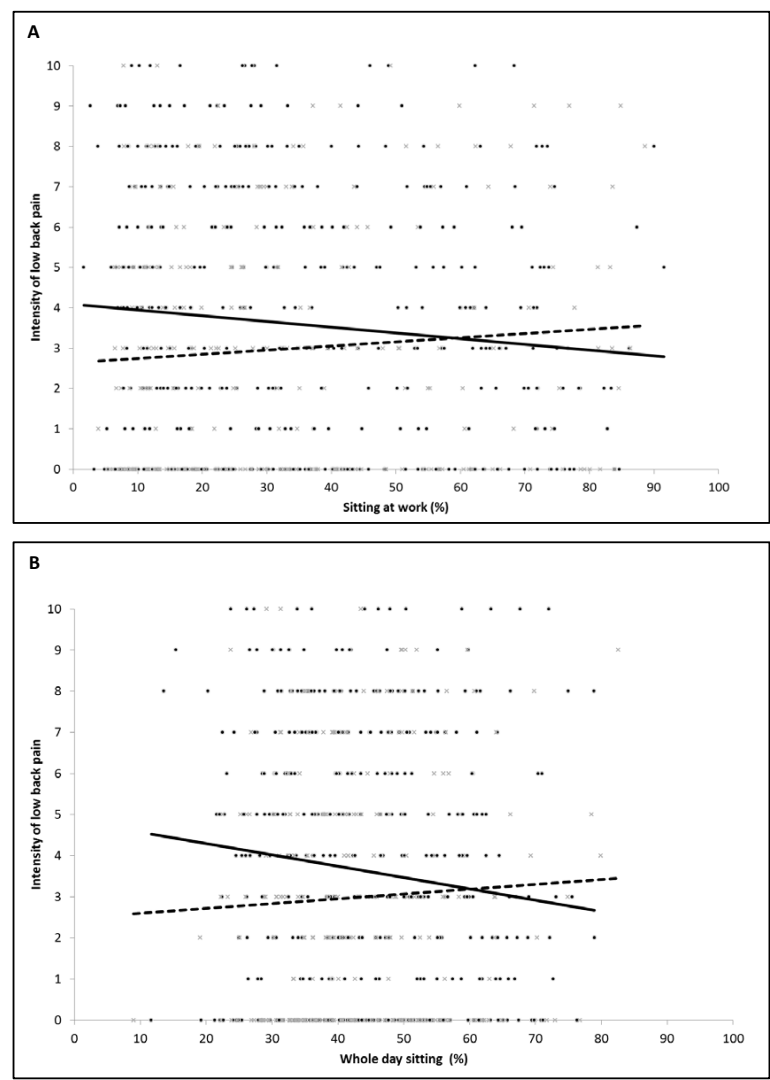

Figures $\mathbf{3} \mathbf{A}$ and $\mathbf{B}$. Scatter plots and regression lines illustrating the crude association between sitting during work $(A)$ and the whole day (B) expressed in percent and pain intensity and stratified on body mass index (BMI): low $<25 \mathrm{~kg} / \mathrm{m}^{2}, \mathrm{~N}=238$; high $\geq 25 \mathrm{~kg} / \mathrm{m}^{2}, \mathrm{~N}=447$. The solid line represents participants in the high BMI category. The dashed line represents the participants in the low BMI category.

Table 3. Crude associations between sitting (total amount and temporal patterns (EVA categories)) during work and for the whole day (waking hours), and the intensity of low back pain (scale 0-10), stratified on low $\left(<25 \mathrm{~kg} / \mathrm{m}^{2}, \mathrm{~N}=238\right)$ and high $\left(\geq 25 \mathrm{~kg} / \mathrm{m}^{2}, \mathrm{~N}=447\right)$ body mass index $(\mathrm{BMI})$. Significant $(\mathbf{P}<\mathbf{0 . 0 5})$ associations are marked with bold.

\begin{tabular}{|c|c|c|c|c|c|c|}
\hline & \multicolumn{3}{|c|}{$\begin{array}{l}\text { Low BMI } \\
\left(<25 \mathrm{~kg} / \mathrm{m}^{2}\right)\end{array}$} & \multicolumn{3}{|c|}{$\begin{array}{l}\text { High BMI } \\
\left(\geq 25 \mathrm{~kg} / \mathrm{m}^{2}\right)\end{array}$} \\
\hline & B & SE & P-value & B & SE & P-value \\
\hline \multicolumn{7}{|l|}{ Occupational sitting } \\
\hline $\begin{array}{l}\text { Total (\% of occupational } \\
\text { hours spent sitting) }\end{array}$ & 0.13 & 0.10 & 0.22 & -0.16 & 0.08 & 0.04 \\
\hline $\begin{array}{l}\text { Brief bursts } \\
(\leq 5 \text { minutes })\end{array}$ & 0.35 & 0.17 & 0.04 & -0.19 & 0.14 & 0.18 \\
\hline $\begin{array}{l}\text { Moderate periods } \\
\text { (>5-20 minutes) }\end{array}$ & 0.17 & 0.14 & 0.21 & -0.21 & 0.11 & 0.051 \\
\hline $\begin{array}{l}\text { Prolonged periods } \\
\text { ( }>20 \text { minutes) }\end{array}$ & -0.01 & 0.10 & 0.89 & -0.07 & 0.07 & 0.33 \\
\hline \multicolumn{7}{|l|}{ Whole day sitting } \\
\hline $\begin{array}{l}\text { Total (\% of whole } \\
\text { day spent sitting) }\end{array}$ & 0.17 & 0.20 & 0.41 & -0.37 & 0.15 & 0.02 \\
\hline $\begin{array}{l}\text { Brief bursts } \\
\text { ( } \leq 5 \text { minutes) }\end{array}$ & 0.70 & 0.26 & $<0.01$ & -0.26 & 0.25 & 0.30 \\
\hline $\begin{array}{l}\text { Moderate periods } \\
\text { (>5-20 minutes) }\end{array}$ & 0.57 & 0.24 & 0.02 & -0.46 & 0.19 & 0.02 \\
\hline $\begin{array}{l}\text { Prolonged periods } \\
\text { (>20 minutes) }\end{array}$ & -0.26 & 0.17 & 0.13 & -0.18 & 0.13 & 0.17 \\
\hline
\end{tabular}

be further explored in future studies with measurement, eg, muscle mass or muscle strength.

To our knowledge, no previous studies have addressed the temporal pattern of sitting in relation to LBP. Our analyses indicated that EVA derivatives reflecting the temporal sitting pattern (ie, brief bursts, and moderate and prolonged periods) were not associated with LBP intensity. This stands in contrast to studies arguing that breaks from prolonged sitting are beneficial for health outcomes (49-51). However, breaks from sitting may increase the exposure to other risk factors for LBP, such as awkward working postures (6, 52). On the other hand, longer uninterrupted periods of sitting may also increase the risk for LBP due to the constrained body posture. Accordingly, prolonged sitting has been shown to be associated with periods of uninterrupted, low-intensity muscle contractions, which may lead to increased blood pressure and increased systemic levels of pro-inflammatory cytokines $(51,53,54)$. The proposed beneficial health effects from breaking up prolonged periods of sitting are consistent with the general notion that sufficient variation in body postures and loads is a necessary prerequisite for good musculoskeletal health $(13,14)$.

The limited importance of sitting for LBP found in our study suggests that LBP likely depends on what workers do when they do not sit. Thus, future research into associations between sitting and LBP should focus on the whole timeline of physical activities and postures, and examine the effect of combinations of different physical activities, including their temporal pattern. Such studies would be particularly warranted among workers that do not sit for considerable parts of their working hours. Also, emphasis should be given to understanding the extent to which a possible effect of sitting is moderated by what workers do when they do not sit. Additionally, prospective studies of associations between sitting and LBP should be encouraged to gain a better understanding of sitting as a possible predictive risk factor.

\section{Methodological considerations}

The present study was based on objective measurements of duration of sitting by use of two tri-axial accelerometers. This allows discrimination of, eg, sitting from lying and standing, and thus minimizes misclassification of exposure. Thus, detailed patterns of sitting (and other activities) can be assessed validly across several days. The relatively large size of the present study population is an additional strength since it allows detection of even small effect sizes with a good statistical power. The study population mainly consisted of blue-collar workers with a reasonably homogenous socioeconomic status, minimizing possible confounding.

However, the study also suffers from some limita- 
tions. The cross-sectional design of the study prevents conclusions regarding causal relationships between sitting and intensity of LBP. An additional limitation is the different time windows for assessing exposure and outcome; the exposure was recorded by accelerometers mounted at the health check and measuring during 2-4 working days after that, and the intensity of LBP was measured retrospectively in a questionnaire. However, we assume the recorded exposure to be representative even for a period preceding the measurements, thus these non-synchronous time windows should not present a serious flaw with respect to the investigated associations. Additionally, these results are derived from a population of mainly blue-collar workers and are therefore not valid in other populations, such as mainly white-collar workers. Data were not available from all included participants on self-reported social support and influence at work. Therefore, we could not completely rule out confounding by psychosocial factors. However, we conducted a sensitivity analysis in a sub-sample $(\mathrm{N}=460)$ of workers allowing additional adjusting for self-reported level of social support and influence at work. This analysis led to numerical and statistical results similar to the final model on the entire population (table 2), suggesting these results to be robust.

\section{Concluding remarks}

The present study found no significant associations between total duration or temporal patterns of sitting and intensity of LBP, neither during work nor for the whole day. Thus, the investigated hypotheses - that an increased amount of sitting will increase the intensity of LBP and the temporal pattern of sitting is important to LBP - were rejected. BMI significantly interacted with sitting and LBP, and a stratified analysis showed weak positive associations among those having a low BMI $\left(<25 \mathrm{~kg} / \mathrm{m}^{2}\right)$, and weak negative associations among those with a high BMI $\left(\geq 25 \mathrm{~kg} / \mathrm{m}^{2}\right)$.

Together, these results suggest that sitting may not be independently associated with peak intensity of LBP, which points towards other exposures being more powerful risk factors for LBP or to the association between sitting and LBP intensity being significantly modified by exposures during non-sitting periods of work.

\section{Acknowledgements}

The authors would like to acknowledge Klaus Hansen, Dorte Ekner, Jørgen Skotte and Julie Lagersted-Olsen for their massive contributions in the collection and preparation of data. The Danish Work Environment Fund supported this study (journal number 04-2014-
09/20140072606) but had no role in the study design or the collection, analysis and interpretation of the data or the writing and submission of this paper.

\section{References}

1. The National Health Profile. https://www.sst.dk/en/ news/2014/ /media/7B4250C3B5C04B6D9D7D374AB13 752A4.ashx. ISBN 978-87-7104-10-4.

2. Lotters F, Burdorf A. Prognostic factors for duration of sickness absence due to musculoskeletal disorders. Clin J Pain. 2006;22:212-221. https://doi.org/10.1097/01. ajp.0000154047.30155.72

3. Andersson GB. Epidemiological features of chronic low-back pain. Lancet. 1999;354:581-585. https://doi.org/10.1016/ S0140-6736(99)01312-4

4. Hartvigsen J, Lings S, Leboeuf-Yde C, Bakketeig L. Psychosocial factors at work in relation to low back pain and consequences of low back pain; a systematic, critical review of prospective cohort studies. Occup Environ Med. 2004;61:e2.

5. Katz JN. Lumbar disc disorders and low-back pain: socioeconomic factors and consequences. J Bone Joint Surg Am. 2006;88 Suppl 2:21-24. https://doi.org/10.2106/00004623200604002-00005

6. da Costa BR, Vieira ER. Risk factors for work-related musculoskeletal disorders: A systematic review of recent longitudinal studies. Am J Ind Med. 2010;53:285-323.

7. Møller SV, Hannerz HF, Hansen AM, Burr HF, Holtermann A. Multi-wave cohort study of sedentary work and risk of ischemic heart disease. Scand J Work Environ Health. 2016;42:43-51. https://doi.org/10.5271/sjweh.3540

8. van der Ploeg HP, Møller SV, Hannerz H, Van der Beek AJ, Holtermann A. Temporal changes in occupational sitting time in the Danish workforce and associations with allcause mortality: results from the Danish work environment cohort study. Int J Behav Nutr Phys Act. 2015;12:71. https://doi.org/10.1186/s12966-015-0233-1

9. Det Nationale Forskningscenter for Arbejdsmiljø. Arbejdsmiljø i Danmark [Work and Health]; 2014 [in Danish]. http://www. arbejdsmiljoforskning.dk/da/arbejdsmiljoedata

10. Hallman DM, Holtermann A, Søgaard K, Krustrup P, Kristiansen J, Korshøj M. Effect of an aerobic exercise intervention on cardiac autonomic regulation: A worksite RCT among cleaners. Physiol Behav. 2016;169:90-97. https://doi. org/10.1016/j.physbeh.2016.11.031

11. Gupta N, Christiansen CS, Hallman DM, Korshøj M, Carneiro IG, Holtermann A. Is objectively measured sitting time associated with low back pain? A cross-sectional investigation in the NOMAD study. PLoS One. 2015;10:e0121159. https:// doi.org/10.1371/journal.pone.0121159

12. Hallman DM, Mathiassen SE, Gupta N, Korshøj M, Holtermann A. Differences between work and leisure in temporal patterns of objectively measured physical activity among blue-collar workers. BMC Public Health. 2015;15:976. 
https://doi.org/10.1186/s12889-015-2339-4

13. Mathiassen SE. Diversity and variation in biomechanical exposure: what is it, and why would we like to know? Appl Ergon. 2006;37:419-427. https://doi.org/10.1016/j. apergo.2006.04.006

14. Toomingas A, Forsman M, Mathiassen SE, Heiden M, Nilsson T. Variation between seated and standing/walking postures among male and female call centre operators. BMC Public Health. 2012;12. https://doi.org/10.1186/1471-2458-12-154

15. Beach TA, Parkinson RJ, Stothart JP, Callaghan JP. Effects of prolonged sitting on the passive flexion stiffness of the in vivo lumbar spine. Spine J. 2005;5:145-154. https://doi. org/10.1016/j.spinee.2004.07.036

16. Claus A, Hides J, Moseley GL, Hodges P. Sitting versus standing: does the intradiscal pressure cause disc degeneration or low back pain? J Electromyogr Kinesiol. 2008;18:550-558. https://doi.org/10.1016/j.jelekin.2006.10.011

17. Makhsous M, Lin F, Bankard JF, Hendrix RW, Hepler MF, Press J. Biomechanical effects of sitting with adjustable ischial and lumbar support on occupational low back pain: evaluation of sitting load and back muscle activity. BMC Musculoskeletal Disord. 2009. https://doi.org/10.1186/1471-2474-10-17

18. Lis AM, Black KM, Korn H, Nordin M. Association between sitting and occupational LBP. Eur Spine J. 2007;16:283-298. https://doi.org/10.1007/s00586-006-0143-7

19. Chen SM, Liu MF, Cook J, Bass S, Lo SK. Sedentary lifestyle as a risk factor for low back pain: a systematic review. Int Arch Occup Environ Health. 2009;82:797-806. https://doi.org/10.1007/s00420-009-0410-0

20. Roffey DM, Wai EK, Bishop P, Kwon BK, Dagenais S. Causal assessment of occupational sitting and low back pain: results of a systematic review. Spine J. 2010;10:252-261. https://doi.org/10.1016/j.spinee.2009.12.005

21. Jørgensen MB, Korshøj M, Lagersted-Olsen J, Villumsen M, Mortensen OS, Skotte J, et al. Physical activities at work and risk of musculoskeletal pain and its consequences: protocol for a study with objective field measures among blue-collar workers. BMC Musculoskelet Disord. 2013;14:213. https:// doi.org/10.1186/1471-2474-14-213

22. Kwak L, Proper KI, Hagstromer M, Sjöström M. The repeatability and validity of questionnaires assessing occupational physical activity--a systematic review. Scand J Work Environ Health. 2011;37:6-29. https://doi.org/10.5271/ sjweh.3085

23. Miranda H, Gold JE, Gore R, Punnett L. Recall of prior musculoskeletal pain. Scand J Work Environ Health. 2006;32:294-299. https://doi.org/10.5271/sjweh.1013

24. Holtermann A, Clausen T, Jørgensen MB, Mork PJ, Andersen LL. Should physical activity recommendation depend on state of low back pain? Eur J Pain. 2014;18:575-581. https://doi. org/10.1002/j.1532-2149.2013.00403.x

25. Nilsen TI, Holtermann A, Mork PJ. Physical exercise, body mass index, and risk of chronic pain in the low back and neck/shoulders: longitudinal data from the Nord-Trondelag Health Study. Am J Epidemiol. 2011;174:267-273. https://oi. org/10.1093/aje/kwr087

26. Thorp AA, Kingwell BA, Owen N, Dunstan DW. Breaking up workplace sitting time with intermittent standing bouts improves fatigue and musculoskeletal discomfort in overweight/obese office workers. Occup Environ Med. 2014;11:765-771. https://doi.org/10.1136/oemed-2014-102348

27. Lunde LK, Koch MF, Knardahl S, Veiersted KB. Associations of objectively measured sitting and standing with lowback pain intensity: a 6-month follow-up of construction and healthcare workers. Scand J Work Environ Health. 2017;43(3):269-278. https://doi.org/10.5271/sjweh.3628

28. Hallman DM, Mathiassen SE, Heiden M, Gupta N, Jørgensen MB, Holtermann A. Temporal patterns of sitting at work are associated with neck-shoulder pain in blue-collar workers: a cross-sectional analysis of accelerometer data in the DPhacto study. Int Arch Occup Environ Health. 2016;89:823-833. https://doi.org/10.1007/s00420-016-1123-9

29. Lagersted-Olsen J, Bay H, Jørgensen MB, Holtermann A, Søgaard K. Low back pain patterns over one year among 842 workers in the DPhacto study and predictors for chronicity based on repetitive measurements. BMC Musculoskelet Disord. 2016;17:453. https://doi.org/10.1186/s12891-016$1307-1$

30. The Actigraph. http://www.theactigraph.com; [updated 2011 Jun 10.]

31. Skotte J, Korshøj M, Kristiansen J, Hanisch C, Holtermann A. Detection of physical activity types using triaxial accelerometers. J Phys Act Health. 2014;11:76-84 https://doi. org/10.1123/jpah.2011-0347

32. Mathiassen SE, Winkel J. Quantifying variation in physical load using exposure-vs-time data. Ergonomics. 1991;34:14551468. https://doi.org/10.1080/00140139108964889

33. Kuorinka I, Jonsson B, Kilbom Å, Vinterberg H, BieringSørensen F, Andersson G, et al. Standardised Nordic questionnaires for the analysis of musculoskeletal symptoms. Appl Ergo. 1987;18:233-237. https://doi.org/10.1016/00036870(87)90010-X

34. Biering-Sørensen F. A prospective study of low back pain in a general population. I. Occurrence, recurrence and aetiology. Scand J Rehabil Med. 1983;15:71-79.

35. Leboeuf-Yde C. Smoking and low back pain. A systematic literature review of 41 journal articles reporting 47 epidemiologic studies. Spine. 1999;24:1463-1470. https://doi. org/10.1097/00007632-199907150-00012

36. Alkherayf F, Wai EK, Tsai EC, Agbi C. Daily smoking and lower back pain in adult Canadians: the Canadian Community Health Survey. J Pain Res. 2010;3:155-160. https://doi.org/10.2147/JPR.S11031

37. Zhang TT, Liu Z, Liu YL, Zhao JJ, Liu DW, Tian QB. Obesity as a Risk Factor for Low Back Pain: A Meta-Analysis. Clin Spine Surg. 2016; Nov 21. Epub ahead of print.

38. Thorp AA, Owen N, Neuhaus M, Dunstan DW. Sedentary behaviors and subsequent health outcomes in adults a systematic review of longitudinal studies, 1996-2011. Am J Prev Med. 2011;41:207-215. https://doi.org/10.1016/j. amepre.2011.05.004 
39. Owen N, Sugiyama T, Eakin EE, Gardiner PA, Tremblay MS, Sallis JF. Adults' sedentary behavior determinants and interventions. Am J Prev Med. 2011;41:189-196. https://doi. org/10.1016/j.amepre.2011.05.013

40. Chou D, Samartzis D, Bellabarba C, Patel A, Luk KD, Kisser JM, Skelly A. Degenerative magnetic resonance imaging changes in patients with chronic low back pain: a systematic review. Spine. 2011;36:S43-S53. https://doi.org/10.1097/ BRS.0b013e31822ef700

41. Heneweer H, Vanhees LF, Picavet HS. Physical activity and low back pain: a U-shaped relation? Pain. 2009;143:21-25. https://doi.org/10.1016/j.pain.2008.12.033

42. Rhodes RE, Mark RS, Temmel CP. Adult sedentary behavior: a systematic review. Am J Prev Med. 2012;42:e3-e28. https:// doi.org/10.1016/j.amepre.2011.10.020

43. Hartvigsen J, Kyvik KO, Leboeuf-Yde C, Lings S, Bakketeig L. Ambiguous relation between physical workload and low back pain: a twin control study. Occup Environ Med. 2003;60:109-114. https://doi.org/10.1136/oem.60.2.109

44. Jensen JN, Holtermann A, Clausen T, Mortensen OS, Carneiro IG, Andersen LL. The greatest risk for low-back pain among newly educated female health care workers; body weight or physical work load? BMC Musculoskeletal Disord. 2012;87. https://doi.org/10.1186/1471-2474-13-87

45. Karvonen MJ, Kentala E, Mustala O. The effects of training on heart rate; a longitudinal study. Ann Med Exp Biol Fenn. 1957;35:307-315.

46. Tanaka H, Monahan KD, Seals DR. Age-predicted maximal heart rate revisited. J Am Coll Cardiol. 2001;37:153-156. https://doi.org/10.1016/S0735-1097(00)01054-8

47. Pejtersen JH, Kristensen TSV, Borg V, Bjørner JB The second version of the Copenhagen Psychosocial Questionnaire. Scand J Public Health. 2010;38:8-24. https:/ doi.org/10.1177/1403494809349858
48. Fogelholm M. Physical activity, fitness and fatness: relations to mortality, morbidity and disease risk factors. A systematic review. Obes Rev. 2010;11:202-221. https://doi.org/10.1111/ j.1467-789X.2009.00653.x

49. Carson V, Wong SL, Winkler E, Healy GN, Colley RC, Tremblay MS. Patterns of sedentary time and cardiometabolic risk among Canadian adults. Prev Med. 2014;65:23-27. https://doi.org/10.1016/j.ypmed.2014.04.005

50. Healy GN, Dunstan DW, Salmon J, Cerin E, Shaw JE, Zimmet $\mathrm{PZ}$, et al. Breaks in sedentary time: beneficial associations with metabolic risk. Diabetes Care. 2008;31:661-666. https://doi.org/10.2337/dc07-2046

51. Henson J, Yates T, Edwardson CL, Khunti K, Talbot D, Gray LJ, Leigh TM, Carter P, Davies MJ. Sedentary time and markers of chronic low-grade inflammation in a high risk population. PLoS One. 2013;8. https://doi.org/10.1371/ journal.pone.0078350

52. Larsson B, Søgaard K, Rosendal L. Work related neckshoulder pain: a review on magnitude, risk factors, biochemical characteristics, clinical picture and preventive interventions. Best Pract Res Clin Rheumatol. 2007;21:447-463. https://doi. org/10.1016/j.berh.2007.02.015

53. Larsen RN, Kingwell BA, Sethi P, Cerin E, Owen N, Dunstan DW. Breaking up prolonged sitting reduces resting blood pressure in overweight/obese adults. Nutr Metab Cardiovasc Dis. 2014;24:976-982. https://doi.org/10.1016/j. numecd.2014.04.011

54. Yates T, Khunti K, Wilmot EG, Brady E, Webb D, Srinivasan $\mathrm{B}$, et al. Self-reported sitting time and markers of inflammation, insulin resistance, and adiposity. Am J Prev Med. 2012;42:1-7. https://doi.org/10.1016/j.amepre.2011.09.022

Received for publication: 14 June 2016 